\title{
Ventricular tachycardia with regular capture beats
}

\author{
Himanshu Mahla, Jayaprakash Shenthar, K R Sunil Kumar, \\ Cholenahally Nanjappa Manjunath
}

Department of Cardiology, Sri Jayadeva Institute of Cardiovascular Sciences \& Research, Bangalore, Karnataka, India

\section{Correspondence to} Dr K R Sunil Kumar, drsunilkumarkr@gmail.com

Accepted 13 March 2014

\section{DESCRIPTION}

A 30-year-old man presented with a 1-day history of sudden onset palpitations. He was haemodynamically stable. Twelve-lead electrocardiography showed wide complex tachycardia with right bundle branch block and left superior axis (figures 1 and 2). Every two wide complex beats were followed by a narrow complex beat and this cycle was repeating. Careful inspection revealed that narrow complex beats were having fixed relationship to wide complexes and among themselves, but there was atrioventricular (AV) dissociation. The patient's echocardiographic examination was normal. $\mathrm{He}$ was reverted to normal sinus rhythm with DC cardio V.150 Joules. Before direct current (DC) cardioversion, verapamil and $\beta$-blockers tried but not successful.

These narrow complexes were capture beats ${ }^{12}$ as they were same as sinus beats (in having a $\mathrm{qR}$ in V1) when the patient was in sinus rhythm after treatment (figure 3). Ventricular tachycardia (VT) localisation was idiopathic left ventricular VT from posterior fascicle, ${ }^{3}$ but regularity of capture beats was the one point that made us doubt our diagnosis. The only explanation we can offer is that patient might be having dual AV node physiology or re-entry occurring at junction. The narrow complex beat may be conducting via the one pathway (interval between preceding wide QRS beat and narrow QRS beat is shorter than the interval between narrow QRS and following wide QRS beat best seen in V1) but at the same time the other site of the circuit is refractory, so re-entry abolishes and V happens with wide QRS. Again after two V's this cycle reappears. Response to DC shock

\section{Learning points}

- Ventricular tachycardia (VT) can rarely demonstrate regular capture beats.

- Fascicular VT is amenable to radiofrequency ablation.

- The diagnostic tetrad of idiopathic LV VT is a) Induction with atrial pacing, b) RBBB with LAD on ECG c) Structurally normal heart and d) verapamil sensitivity.

- Focal re-entry is principal mechanism of Idiopathic LV VT.

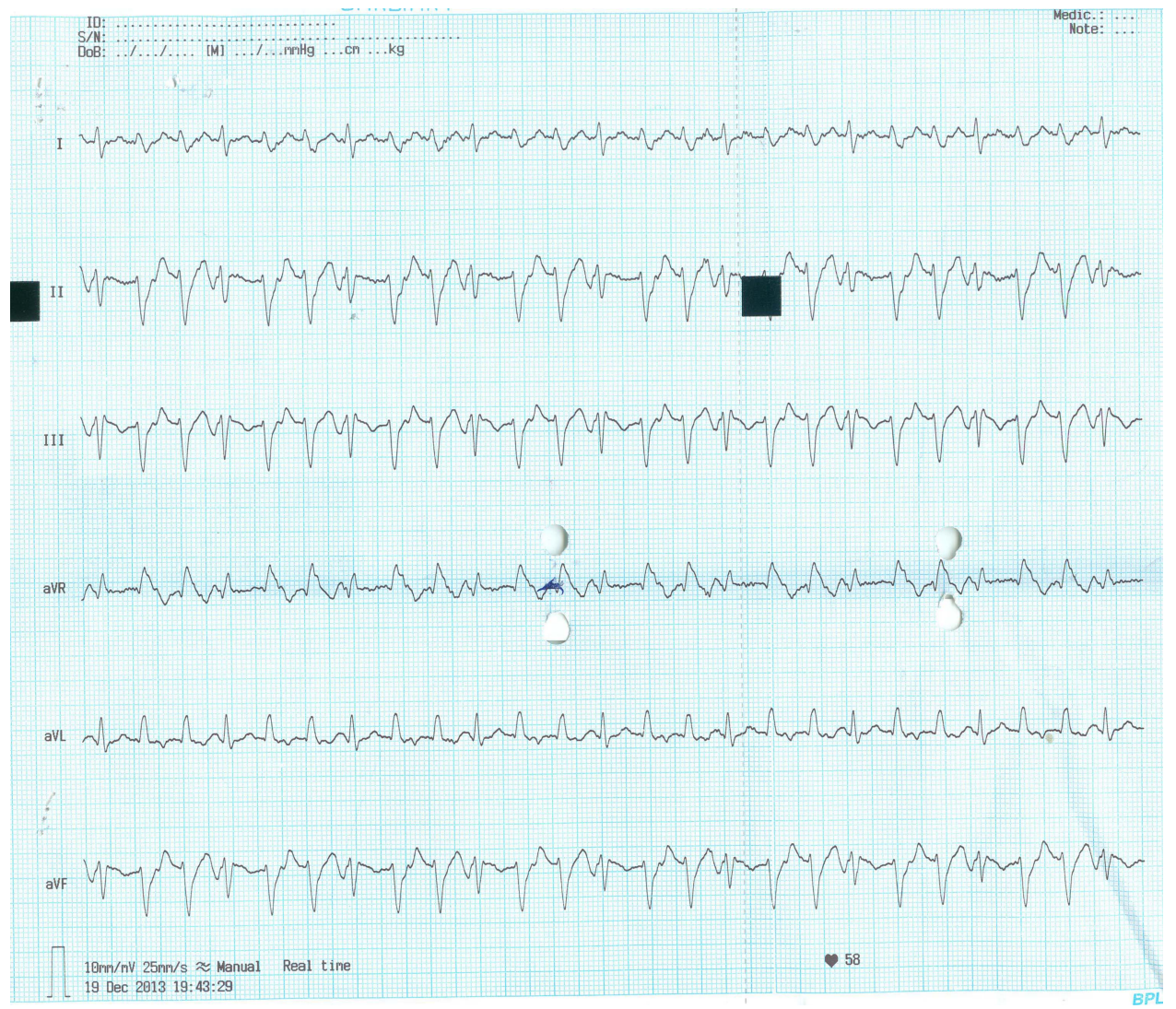

Figure 1 Six-limb leads ECG showing ventricular tachycardia with regular capture beats and left axis deviation.

To cite: Mahla $\mathrm{H}_{\text {, }}$

Shenthar J, Sunil Kumar KR, et al. BMJ Case Rep Published online: [please include Day Month Year] doi:10.1136/bcr-2014204121 


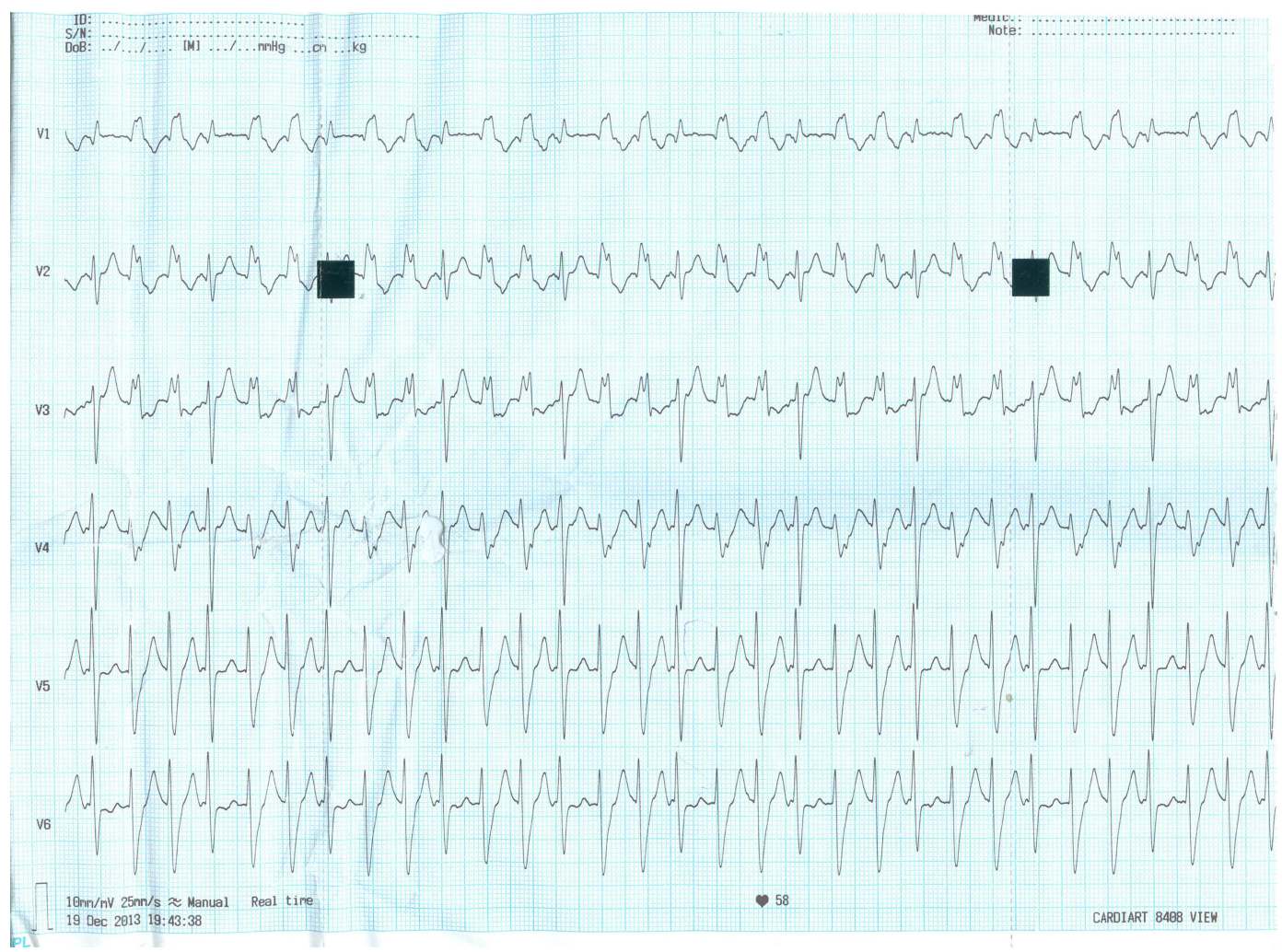

Figure 2 Six precordial leads ECG showing right bundle branch block ventricular tachycardia with regular capture beats having qR in V1.

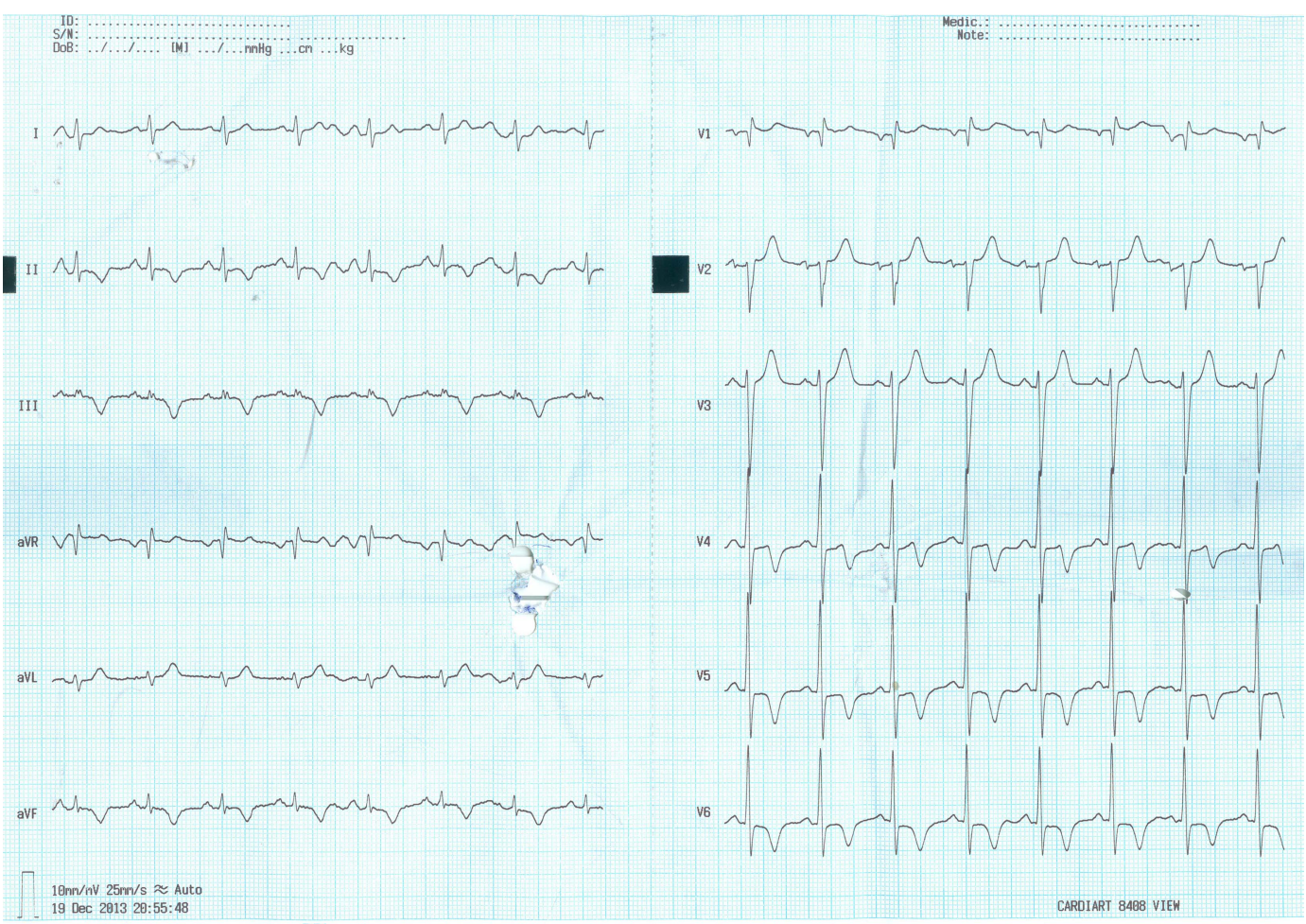

Figure 3 Twelve-lead ECG after conversion to sinus rhythm with inferior axis and qR in V1. 
confirms re-entry as a mechanism. Cardiac MRI of the patient was normal proving VT with structurally normal heart. This patient underwent electrophysiological studies which showed fascicular VT and successfully ablated. Although unexplainable, $\mathrm{AV}$ node did not demonstrate re-entry.

Acknowledgements The authors are thankful to Dr Neha Godara.

Contributors HM was involved in drafting the manuscript. JS came up with the concept and idea of writing the case report. SKKR carried out the corrections. CNM finalised the manuscript.

Competing interests None.
Patient consent Obtained.

Provenance and peer review Not commissioned; externally peer reviewed.

\section{REFERENCES}

1 Nabar A, Rodriguez L-M, Timmermans C, et al. Capture and fusion beats during atrial fibrillation and ventricular tachycardia. Heart 2000;84:e1.

2 Becker SN, Alzand R, Manusama APM, et al. An "Almost Wide" QRS tachycardia. Circ Arrhythm Electrophysiol 2009;2:e1-3.

3 Srivathsan K, Lester SJ, Appleton CP, et al. Ventricular tachycardia in the absence of structural heart disease. Indian Pacing Electrophysiol I 2005; 5:106-21.

Copyright 2014 BMJ Publishing Group. All rights reserved. For permission to reuse any of this content visit http://group.bmj.com/group/rights-licensing/permissions.

BMJ Case Report Fellows may re-use this article for personal use and teaching without any further permission.

Become a Fellow of BMJ Case Reports today and you can:

- Submit as many cases as you like

- Enjoy fast sympathetic peer review and rapid publication of accepted articles

- Access all the published articles

- Re-use any of the published material for personal use and teaching without further permission

For information on Institutional Fellowships contact consortiasales@bmjgroup.com

Visit casereports.bmj.com for more articles like this and to become a Fellow 